\title{
"My child will be respected": Parental perspectives on computers and education in Rural India
}

\author{
Joyojeet Pal • Meera Lakshmanan • Kentaro Toyama
}

Published online: 28 April 2009

(C) The Author(s) 2009. This article is published with open access at Springerlink.com

\begin{abstract}
Public spending on computer centers in rural Indian public schools raise questions about the value of expensive modern technology in extremely resourcestrapped environments. Arguments for or against providing computers in low-income schools have appeared in policy circles, academia, teacher conferences, and philanthropic discussions, with passionate rhetoric from all sides. We present the results of a qualitative study of computer-aided learning centers in schools catering primarily to Below Poverty Line (BPL) families in four districts of rural Karnataka, South India. Here, we held a series of openand close-ended discussions with parents of children from these schools on issues such as aspirations, quality of schooling, and the perception of computers more generally. The research reveals a range of voices on hopes for the next generation, perceived value of computer courses and higher education, and the perceived changes in villages after the arrival of computers in their local schools. It emerges that for many parents, the computer has an immense symbolic value - separate from its functional value - that is tied to
\end{abstract}

This material is based upon work supported by the National Science Foundation under Grant No. 0326582

J. Pal $(\bowtie)$

Center for Information and Society, University of Washington,

Seattle, WA, USA

e-mail: joyojeet@gmail.com

M. Lakshmanan

Azim Premji Foundation,

Bangalore, India

e-mail: meeragargi@gmail.com

K. Toyama

Microsoft Research India,

Bangalore, India

e-mail: kentaro.toyama@microsoft.com social and economic ascendancy. We find that this symbolic value derives from associations that parents imbibe from their various interactions with people using computers in a range of situations. We find in our interviews a heightened sense of mystique over the technology and its potential, across people with varying levels of first-hand experience and understanding of computers. We find that notions of change and hope are situated within an environment of great fear about the future of agriculture. We argue here that this, alongside a widespread existing discourse about computers in media and public life in India, mostly emerging from urban middle-classes ideas around technology, help spur a strong sense of expectation that the computers can dramatically change social prospects even among the poorest and most excluded. From competing with English as the gateway to power, to impacting dowry costs for female youth, interviews show a myriad of expectations from technology, creating what we see as a strong case for a nuanced look at the discourse and mythology of computers and technology in developing regions.

Keywords Developing nations · Human factors ·

Rural areas $\cdot$ Technology social factors

\section{Introduction}

Computer-aided learning (CAL) projects are active in over 20,000 public primary schools in India. These programs are designed as aids to the curricular program in schools and typically include a computer center with 3-5 machines set up per primary school of about $200-400$ children in a rough 1:50 machine/child ratio. The general model varies regionally; in Karnataka where this research was conducted, the 
state government started its initial pilot in 2002 in schools through an implementing agency - the Azim Premji Foundation (APF), a local NGO specializing in social investments in primary education. ${ }^{1}$ and paid for all infrastructure, fixed cost, and three-years worth of hardware maintenance cost for the CAL centers. In addition, all the schools were provided for the first year a 'support teacher' to oversee the activities inside the CAL center and provide basic maintenance for the computers. After the first year the schools had to raise their own funding for the support teacher and any other maintenance expenditures for the CAL center.

The typical CAL class has about 3-5 children sitting at each computer in the lab, often with a supervising teacher. The multimedia content that the students use at their workstations ranges from curricular mathematics, sciences, and languages, and is usually delivered in the local language (Kannada). In Karnataka, the entire set up and initial functioning of the CAL centers, as well as the content creation, are managed by the APF on behalf of state government's education department. APF also has similar contracts to build and operate CAL centers for several other states in India including Orissa, Tamil Nadu, Punjab, and Rajasthan. Teachers as well as school administrators are provided training sessions at the educational department's block offices for the use of the content and administration of the centers in general. Although the program is envisioned for use by all primary school children, it is typically children from the $3^{\text {rd }}$ grade and above who are given weekly computer classes.

CAL centers are not available in all schools throughout Karnataka. Schools are selected based on a number of criteria including the availability of electricity, infrastructure, and a reasonable adequacy of full-time teachers. In addition, the village as a whole has to support the computer center-before a CAL center is established in a village school, officials from the state government as well as from APF make visits to the school and speak with parents and teachers to gauge interest in getting computers. A meeting of the village council and parents is typically assembled where parents are asked for a commitment of their support to the CAL project - which mainly includes an undertaking on their behalf to raise funds for any maintenance expenditures for the computers such as electricity bills, and for the salary of the CAL center support teacher (usually in the range of US\$ 50 per month) after the first year of government support. If the visiting officials are satisfied with the physical conditions of the school as well as the village's commitment to keep the CAL program alive, they recommend a CAL be set up in the school. While there are various pools of money from which the

${ }^{1}$ The APF had itself been providing CAL centers in public schools with its own independent funding since 2001 .
CAL centers are funded, the main fund for the project comes from a Rs. 15,00,000 ( US\$ 37,500) annual fund per for computers district from the Sarva Shiksha Abhiyan (SSA). Each of the 27 administrative districts in Karnataka ${ }^{2}$ has between 1,000-2,500 government-run primary schools and each CAL center (assuming that building infrastructure exists) costs about $\$ 1,500$ to set up. This roughly means that about 25 CALs each year can be added through this budget. By 2007, about 5,000 primary schools ${ }^{3}$ representing roughly $10 \%$ of all government schools in Karnataka had some form of CAL installed since the start of the program.

In this study, we present a sub-set of a larger project interviewing parents, teachers, and other stakeholders in issues around CAL centers in Karnataka. We specifically focus on parents' impressions of the effects of the CAL project on the lives of their children.

\section{Previous work}

This work differs from what has come to be more typical ICTD research since it does not do an impact analysis of a technology in use, nor speaks of the potential for a techology. We are more interested in the second-order impacts of technology, in this case specifically computers in schools. Essentially our empirical data here is a frame for us to look at the discourse of technology in India, and use that potentially as a proxy for technology in development more broadly. This is an area of surprisingly little existing work.

There are several bodies of scholarly work that contribute to and take further this research, but given our interest primarily in the ICTD community, there are three bodies of existing work we see this work as immediately relevant to. The first is the work on computer-aided learning in India and on the impact of computer use on children. Second is literature in the science and technology studies space on discourses around technology. The third is the existing literature on ICTD in India. We find that while a lot of excellent work has chronicled or proposed the upshots of ICTD projects in India from various aspects, there has been little looking at the popular understanding of technology in rural India and how that has impacted such implementations.

Finally, yet another area of relevance that we allude to, but make no definitive claims on, is that of 'bang for the

\footnotetext{
${ }^{2}$ Karnataka has 34 administrative divisions for education, some districts are split into multiple sub-districts because of their size and population.

${ }^{3}$ Department of School
} 
buck' on state investments into schemes for increasing school enrollment. This is indeed an important emergent theme, especially given the plethora of anecdotal evidence we found from a variety of stakeholders throughout this research suggesting that children's attendance and interest in schools has risen after the computers have arrived. Yet, given that attendance ties to longevity in the schooling system, it is a question that needs answering through a different set of empirical tools than those used here.

\subsection{Computer-aided learning in India}

Studies of CAL projects in India have covered outcomes in computer-aided learning generally (Linden et al. 2003), the social and organizational factors impacting the success and failure of such projects (Brewer et al. 2006), and the learning impacts of children with no prior experience with computers (Inamdar 2004). On the more general issue of the learning and social impacts of computers among children, the academic literature leans towards a more critical look (Cuban 2001) from a policy perspective. On learning issues, however, there is general agreement that establishing causality in improved learning outcomes because of computers is generally difficult and that there are two sides to learning outcomes in schools (Wartella 2000) as well on the overall cognitive and developmental side for young children using computers (Attewell and Battle 1999).

\subsection{Discourses of technology among parents \\ about technology use for their children}

A lot of work on computers and family has focused on access issues across various income categories (Becker 2000; Linebarger and Chernin 2003). Some work however has looked at parents' attitudes towards computer use among children, especially among middle-class Americans (Lindlof 1992; Downes 1999). Significant work has been focused at the discourse at the macro-level of state policies with an eye on informing or critiquing policy initiatives (Coley et al. 1997; Resnick et al. 1998; Culp et al. 2005). There is also a good amount of micro-level work that looks at computers and children within the family; much of this work has been more focused towards computer games (Prensky 2003; Rosas et al. 2003; Selwyn 2003) in homes in the developed world. Finally, there has been important work in looking at the role of children in the adoption of technology by adults (Selwyn 2004). This paper complements this line of work by examining parental views on CAL. The dichotomy of opinion of games as valid learning technology is less relevant in our sample, given that the socially undesirable conceptions of videogames are less stereotypical in communities relatively new to technology (Lawry et al. 1995).

\subsection{ICTD in India}

India has probably been better represented in ICTD research than any other country in the world. Some of the earliest and most optimistic prophecies of ICTs' transformative potential came from India (Arunachalam 1999; Bhatnagar 2000; Singhal and Rogers 2001; Thamizoli and Balasubramanian 2001; Harris et al. 2003; Garai and Shadrach 2006), and over time, the keenest critical looks at the hype over ICTD also came from research centered in India (Keniston 2002; Benjamin et al. 2006; De 2007; Vasudevan 2007). There are several reasons why ICTD work has been particularly important in India - the most obvious is the perceived role of the technology sector in economic growth in India since the 1990s (Ganguly and Pardesi 2007) and the consequent deepening discourse of technology as being an important part of continued growth and social development in India. This has led to a number of projects investing in technology and development in India, partly from the changing nature of philanthropic funding in development causes due to technology companies' growing investments in social investment in their own domain areas. Thus, ICTD work expanded both in human resource development areas such as the CAL and other types of projects in education (Kam et al. 2007), but also in service delivery domains such as healthcare (Chandrasekhar and Ghosh 2001), microfinance (Sathe and Desai 2006) and agricultural productivity (Meera et al. 2004; Ramamritham et al. 2006; Gandhi et al. 2007).

\subsection{Key contributions}

Very little published scholarly work on ICTD has been able to provide empirical evidence of poverty alleviation for people working in primary sectors as an outcome of injecting technological innovations in their lives. An important exception has been the work on cell-phone technology reducing price fluctuations in the fishing sector (Jensen 2007). Examinations of funding priorities of governments seeking new approaches to economic development or companies investing their philanthropic and research resources on emerging markets helps explain some of the supply-side factors, there is practically no research on the demand-side, or what makes the people who are clients of these projects enthusiastic about them.

To approach these issues, we look at how rural parents with no first-hand experience using computers understand their uses in their children's lives. Our novel contributions here are in our descriptions of the places from where rural populations gain their information on technology, and how these in turn impact the imagination of technology and the consequent associated aspirations. We situate our analysis within existing conceptions of power and class, with regard 
to the village community and its relationship with the school and the teachers. Finally, this research brings out important issues in the perception of agriculture both economically and in terms of class, and the intersection of technology with it. These voices are valuable not only to the discussion on CAL programs (which have not typically tended to look at second-order impacts of the interventions), but also more generally to ICTD in India and elsewhere.

\section{Methodology}

The research was conducted only in schools with projects coordinated by the Azim Premji Foundation for the government of Karnataka in south western India, to avoid bias caused by differences in implementation. We selected the four districts of Shimoga, Bangalore Rural, Bellary, and Kodagu, based on regional demographics as well as the number of competed years of the CAL program at these locations. Though a combination of research instruments were used in this project, this paper discusses only the outcomes of the parent interactions, for which the main tool used was an open-ended questionnaire administered to parents of children in neighborhoods around where computer-aided learning centers had been established by the state government.

\subsection{Instrument design}

The data presented is based on opinions from 173 respondents to a structured, open-ended questionnaire. The questionnaire was designed based on 20 free-form conversations with parents, four focus groups, followed by 20 structured interviews based on themes that emerged from these conversations. These preparatory interviews and focus groups were conducted in January 2007 in Shivanahalli and Karahalli, two of the locations in the current sample. Most interviews were preceeded by general conversation about schooling, followed by more specific discussions about the computer aided learning programs and the computers themselves. Eight of these discussions were conducted on site in a rural school, and the remaining were done at the homes of parents. Following this, the instrument was tested with another eight participants in May 2007, and with some minor modifications, the final questionnaire was designed in June 2007 of which the data from 173 parents is used for analysis here. From the original sample of 20 mothers in the free form interviews, we interviewed 10 again in the second phase in June to try and understand some of the changes over time and to check for consistency of the responses. A separate questionnaire was created for a comparison group of locations without the
CAL program, which deleted some questions and added others as necessary.

The main themes that emerged from the free form discussions in January can be broken into two categories. Some issues were of overarching lifestyle questions that impacted parents' interest in schooling and their inclination to send children to school:

1. The issue of an existing crisis in agriculture and a consequent interest in investing in children's schooling

2. Familiarity with the idea of computers, but a very limited understanding of a computer's function

The specific issues that emerged with regard to computers included the following:

1. A belief that the CAL program was increasing their children's interest in school

2. The computer as an artifact of pride in the village, and a symbol of the school's rise in status

3. Gender dimension to the use of computers-such as selective willingness to spend for computer classes by gender, concerns about the dowry implications of computer education

Our final questionnaire was prepared around these themes to explore and understand them better, and was administered by an interviewer in Kannada, the local language. Each interview took between 45-120 minutes.

\subsection{Sampling and recruitment}

Our primary interest was with rural schools. Thus, to get as broad a rural computing experience as possible, we selected four districts in Karnataka-Bangalore Rural, Bellary, Shimoga, and Kodagu for our sample. Of these, Bangalore Rural is a water-shortage affected agricultural area which also has the increasingly common characteristics of proximity to a large metropolitan area. Kodagu was selected because the economy there is primarily coffee and rubber, and most of our participating parents were estate labourers. Shimoga was selected as a remote agricultural inland area with limited urban connection. Bellary was selected as it is a mining region, and a number of the local residents have livelihoods dependent on the nearby steel industry (Fig. 1).

The schools themselves were selected based on the number of years that the school had the CAL program. Three comparison group schools were selected-two in Bangalore Rural, one in Bellary. Parents were selected by going through student registers for classes 5, 6, and 7 in schools and looking for the children's homes in the village to see if someone would speak to us. Grades 5-7 had a higher probability of children who had actually used computers, unlike younger grades where the teachers 


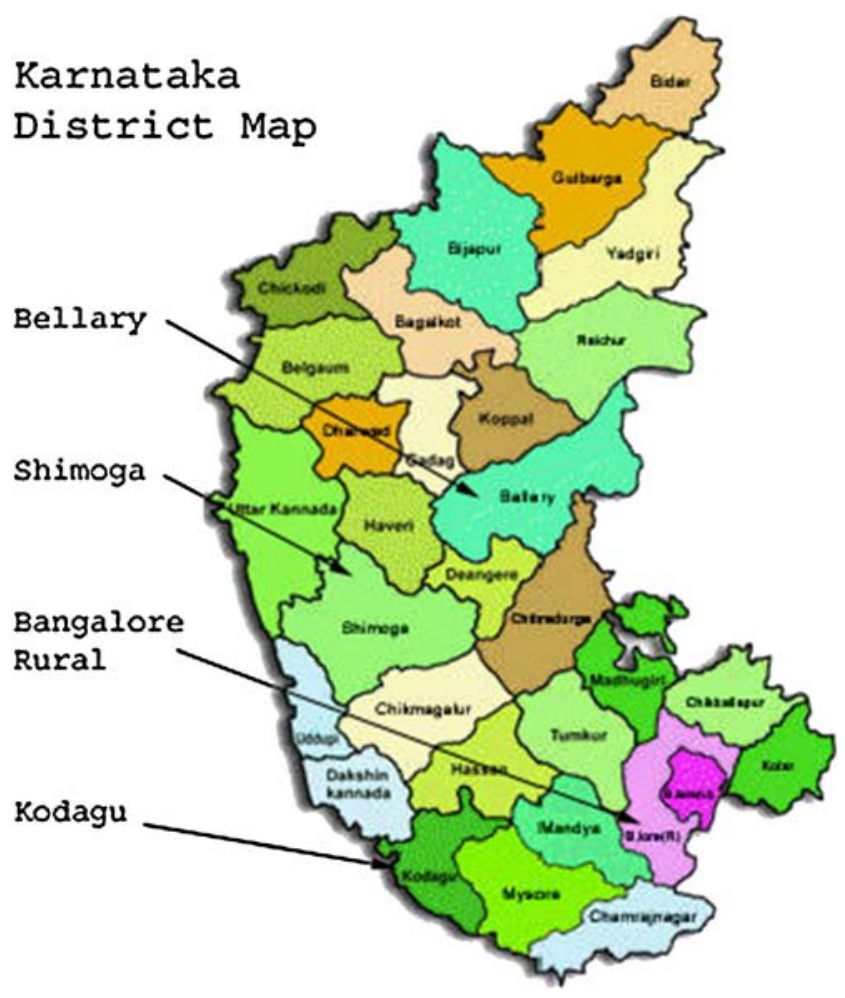

Fig. 1 Map of sampled districts. Map Source: Government of Karnataka, Dept. of Education Website

sometimes did not allow computer usage. The response rate for the entire sample was $89 \%$. Here is a quick description of some of the important statistics about the selected districts: (Table 1)

The statistics here indicate that overall, as far as districtslevel figures go, Bangalore Rural was the most 'advanced' in overall terms of income and other developmental factors from within our sample, and Bellary was the most backward, as seen above through the high out-of-school rates, smaller ratio of schools to population of children, as well as lower attainment than other districts on math and language learning.

However, these figures can be slightly deceptive because of the nature of our sample. Indeed, the villages selected in Bangalore Rural were among the most affluent from our sample, but the villages in Bellary were not necessarily the poorest due to existence of a major steel factory around the villages where our research was conducted. Similarly, despite the comparatively superior indicators for Kodagu, the parents in this sample are comparatively poorer as both surveyed schools were for children of estate laborers (Table 2).

\subsection{Sensitivity of interview questions}

The interview process was challenging for us as well as for the parents - and we feel it is important here to add a note on this, because we were often not just perceived as researchers but as proxies for what technology did. As outsiders to the villages asking questions about the computers and the children, we were frequently the first people from outside of the village to ever interview several of the respondents and the fact that we asked questions about technology and schooling further put us in the realm of conspicuous intervention than a more benign ethnography. As our work proceeded, it was also clear that we were representations of the aspirations we were often researching, as parents turned to us with the familiar response of "I would like my children to be like you when they grow up"

There are consequently not only biases inherent in the study, but also an important human element in peoples' expectations from the technology and their retelling of these to us as outsiders. One particularly difficult issue for us to reconcile with was the grimness of the future prospects for many of the children. For instance, one uncomfortable question that we discuss further down this paper was that of migration. Over three fourths of the parents were keen that their children migrate away from the villages towards the cities. Most of these parents mentioned specific goals and aspirations for their children's career paths. However, many of the same parents later in the interview discussed issues of migration and the poor

Table 1 Profiles of sampled districts

\begin{tabular}{lcccc}
\hline & BR & KO & SH & BE \\
\hline Population (million) & 1.89 & 0.55 & 1.64 & 2.03 \\
$\begin{array}{l}\text { Literacy Rate (\%) } \\
\begin{array}{l}\text { Children of school age } \\
\text { currently out of school (\%) }\end{array}\end{array}$ & 64.7 & 77.9 & 74.5 & 57.4 \\
$\begin{array}{c}\text { Percent children enrolled } \\
\text { in private schools }\end{array}$ & 12.7 & 18.2 & 7.7 & 10.4 \\
$\begin{array}{c}\text { Percent school children } \\
\text { reading basic Kannada }\end{array}$ & 66.9 & 70.8 & 72.5 & 44.7 \\
$\begin{array}{c}\text { Percent Schoolchildren } \\
\text { reading basic English }\end{array}$ & 18.2 & 3.0 & 13.0 & 5.2 \\
$\begin{array}{c}\text { Percent schoolchildren able } \\
\text { to do primary-level math }\end{array}$ & 57.5 & 55.6 & 52.6 & 40.2 \\
$\begin{array}{c}\text { Number of children } \\
\text { per school available }\end{array}$ & 142 & 211 & 153 & 314 \\
$\begin{array}{c}\text { Percent population with } \\
\text { some high-school or more }\end{array}$ & 16.1 & 20.9 & 20.3 & 12.7 \\
\hline
\end{tabular}

${ }^{\mathrm{a}} \mathrm{X}$-axis codes: BR: Bangalore Rural, KO: Kodagu, SH: Shimoga, BE: Bellary

${ }^{\mathbf{b}}$ Defined as percent children in Grades 3-5 who can read basic texts their native language (ASER Survey 2007)

${ }^{\mathbf{c}}$ Defined as percent children in Grades 3-5 who can read the basic sentences in English (ASER Survey 2007)

${ }^{\mathbf{d}}$ Defined as percent children in Grades 3-5 who can read the basic sentences in English (ASER Survey 2007)

Source: Govt. of Karnataka, Dept. of School Education 2005 data 
Table 2 Respondent profiles

\begin{tabular}{|c|c|c|}
\hline & $\begin{array}{l}\text { Respondent } \\
\text { occupations }\end{array}$ & CAL Project functioning \\
\hline $\mathrm{BR}$ & $\begin{array}{l}\text { Small farmers, } \\
\text { casual laborers }\end{array}$ & $\begin{array}{l}\text { Mixed CAL projects (some } 5 \text { yrs or } \\
\text { older, some } 1 \text { year or less) High } \\
\text { faculty involvement in CAL }\end{array}$ \\
\hline $\mathrm{KO}$ & Estate laborers & $\begin{array}{l}\text { All CAL projects 4-yrs or older High } \\
\text { faculty/school involvement in CAL }\end{array}$ \\
\hline SH & Small farmers & $\begin{array}{l}\text { All CAL projects 2-years or newer } \\
\text { Moderate faculty attendance in school }\end{array}$ \\
\hline $\mathrm{BE}$ & $\begin{array}{l}\text { Estate laborers, } \\
\text { factory workers }\end{array}$ & $\begin{array}{l}\text { All CAL projects } 1 \text {-years or newer } \\
\text { Low faculty involvement }\end{array}$ \\
\hline
\end{tabular}

${ }^{\mathrm{a}} \mathrm{y}$-axis codes: BR: Bangalore Rural, KO: Kodagu, SH: Shimoga, BE: Bellary

prospects of local migrants who often ended up as unorganized laborers in big cities. In such conversations, parents often confronted their own fears about the aspirations they set for their children.

\section{Analysis}

The analysis of the data was done by manually coding all the responses. For instance, a response was coded as follows:

Question:

"Have you ever thought of putting your child in a private school? Why or why not?"

Answer:

"Yes, I have thought about it but income is an issue. For a while, I put my younger son into private school, but had to remove him too. This school is good enough, but does not have the same discipline as the private school."

Codes:

*Stated preference for private school

*Economic barrier to moving to private school

*Opinion of private schools being better disciplined

* Some experience with a private school

Most of the analysis presented here includes tabulations of some of the codes as well as excerpts from interviews. The use of tabulations allows us to place some context of scope, rather than offer statistically significant trends. We followed the themes established at the end of our initial set of interviews as a result, our analysis here does not present a linear set of conclusions, rather some overarching themes that help understand the environment that the CAL interventions are happening in. These refer both to the socio-economic pressures in general that impact the perceptions of schooling, as well as specifically to the relationship of villages with the schooling system and to interventions introduced through it. Thereafter, we turn to more specific themes related the CAL program and peoples' opinions of this experiment both in terms of its perceived short term impacts and its long-term scope in the lives of their children.

\subsection{Overarching themes: Shift from agriculture}

To set the context of what people's expectations are from the schooling system, we found that parents' concerns about the economy were illuminating. As would probably true for most recent decades, we had expected that a sizeable number of respondents would mention a preference for their children moving away from their traditional occupations, but the scale was surprising. Only 1 participant from the 117 respondents directly involved in agriculture specified a preference for their child to work in agriculture. The desire to move away from agriculture is not a surprising trend overall, especially in areas around growing cities like Bangalore with a striking urban affluence. Yet, we found that it wasn't landless casual laborers, a traditionally vulnerable group, which was most anxious about their children's continued prospects in their trade. It was on the contrary small land-holding families that were most concerned. In three of the four districts that we researched, such land-holding was multi-generational and traditional, and yet, of the 70 land-holding agriculturists, not a single parent wanted their child to continue in agriculture as their primary source of income. A recurrent comment on questions like this was "We are suffering in agriculture. Why must our children suffer?"

It is difficult to precisely quantify how much of a 'trend' without presenting corresponding data on other occupations, but quite opposed to a general response where people tend not to prefer their children continue their vocation, in this case there was actually a fear among parents that their children may end up having to work in their own job sectors. To explore this further, we included the related next question, which would be parents' views on migration, given that most non-agriculture sector jobs necessitate moving to urban areas, further given that migration away from traditional homes in the villages we were conducting research was not seen as socially very desirable. We see in Table 3, the responses on migration strengthen the validity of the responses on agriculture.

We find in Table 3 a strong preference for children to migrate away, and further that this as a trend is more pronounced among parents in agriculture against those not. The desires to move geographically and occupationally combine to incentivize parents to be very interested in 
Table 3 Stated desire for children to migrate by occupation of parent

\begin{tabular}{llll}
\hline & NR & $\begin{array}{l}\text { Prefers child } \\
\text { migrate away } \\
\text { from village }\end{array}$ & $\begin{array}{l}\text { Prefers child } \\
\text { stay in the } \\
\text { village }\end{array}$ \\
\hline $\begin{array}{c}\text { Agriculturist } \\
(\mathrm{n}=70)\end{array}$ & $7.1 \%$ & $80.0 \%$ & $12.9 \%$ \\
$\begin{array}{c}\text { Agriculture labor } \\
(\mathrm{n}=47)\end{array}$ & & $85.1 \%$ & $14.9 \%$ \\
$\begin{array}{c}\text { All agriculture } \\
(\mathrm{n}=117)\end{array}$ & $4.3 \%$ & $82.1 \%$ & $13.7 \%$ \\
$\begin{array}{c}\text { All non-agriculture } \\
(\mathrm{n}=56)\end{array}$ & $3.6 \%$ & $67.9 \%$ & $28.6 \%$ \\
\begin{tabular}{c} 
Total $(\mathrm{n}=173)$ \\
\hline
\end{tabular} & $4.0 \%$ & $77.5 \%$ & $18.5 \%$ \\
\hline
\end{tabular}

developments in the education system, especially schemes aimed at increasing the ability of children to do well in schooling more broadly. For most parents, the introduction of CAL is a step towards expanding the quality of schooling and making children more competitive for office jobs.

Though this cannot yet be empirically tested, the implication here is that the introduction of computers in rural schools may indirectly contribute to children's longevity within a schooling system that is seen by parents as increasing their occupational options. $91.9 \%$ of all interviewed stated that they would like to see their children get college degrees and, were willing to spend a median of Rs. 5,000 ( US\$100) per year towards higher education per child. Though these figures emerged from the discussions, less than $20 \%$ of the parents had actually started allocating away funds for future use in children's education, less in proportion than parents who had started saving money for daughters' dowries.

We tried to understand what specific jobs parents perceived as both desirable and attainable, given the possibilities that computers were seen as opening up. We found that despite the apparent centrality of technology to the thought process behind the modernization of schools and its perceived role in the migration away from agriculture (as well as the inherent bias in our interviews being centered around technology questions) the typical preferred occupations were rarely in jobs related to computers. The overwhelming preference was for government jobs, both for male and female children. A relatively docile career path of government occupation may seem the antithesis of progress in a liberalizing India, but there is more to the choice than is immediately apparent.

The drive away from agriculture is first seen through the lens of stability, and thereafter from that of high income. Government positions in India are known to be lifelong appointments with levels of income that are fairly high by rural standards. Unlike the metropolitan conception of government jobs as not being the most prestigious, in rural areas being a state official is usually a thing of reasonable pride. One respondent used a famous idiom from Indian cinema to explain his preference for a government job, "We think about it this way, a government job is a racehorse for long races. It never goes very fast, but it always stays until the end."

Top aspirations of parents on jobs for male children are: government job, factory job, teacher. There was some regional variation on aspirations. People in rural parts of Shimoga, Bangalore Rural and Kodagu had a fairly low opinion of private sector jobs, partly because all the villages sampled from those locations were primarily rural, and not a single household from those had a primary wage owner working in any industrial sector. In comparison, the proportion of parents preferring office or factory jobs made up almost half the responses in the steel-belt district of Bellary. Within the realm of government jobs, there was a fair amount of variation: while some parents specifically mentioned desk jobs at district headquarters, others wanted their sons to have jobs as policemen or bus conductors, either of which would be permanent positions. In the more interior villages, these types of job associations with the government were definitely more pronounced, since the face of the state is often only seen through these workers.

For female children, the top preferences were: teacher, nurse, or housewife. The comparatively lower preference for government (desk) jobs among females is explained by the fact that there are rarely female government officials visiting the village, and the general assumption is that for females, a government job would typically be a teaching position in a government school. There was some reporting of parents wanting their daughters to be 'engineers' but when probed, ideas of what an engineer did were somewhat unclear, and the rationale behind wanting to do engineering (as with medicine) was the social respect behind those professions.

Overall, the data from discussions on this issue highlighted that doing just about anything outside of agriculture would be preferred (the exception being urban labour professions - about $55 \%$ of all participants said they would rather be agricultural daily wage laborers than work in urban unorganized labour). Parents also felt that generally having a school education instantly raises a person's ability to earn, though both teachers and young graduates interviewed in the process of this research tended to disagree with that.

We asked parents to try and comment in income terms what they felt an education could buy, and asked them to comment on what a typical high school, or college graduate ought to earn. We find that parents spoke of education as having extremely high payoff. Parents stated that they expected that a starting monthly salary for a high school 
graduate was about $25 \%$ higher than that of a householder small farmer or an agricultural laborer (a median multiplier of 1.25 for about 111 respondents). For a college graduate, a starting monthly salary was valued by parents at twice what a small farmer would make. There was some undervaluation of a farmer's monthly salary, perhaps in part to emphasize the interviewees' own dissatisfaction with agricultural income. Interviewees also stressed repeatedly the idea that a farmer was seen as less respected in society than a 'job holder' (generally meaning an office worker).

There are two key points that emerge from the discussions on the overall subject of occupation, and they lay a foundation for our further investigation into attitudes towards PCs. First, we found that there is an extremely sharp drive towards more schooling and an almost $80 \%$ prevalence of parents stating a desire for their daughters to be preparing themselves for some career regardless of whether marriage was a pre-destined eventuality. Second, we found that much as parents talked about the importance of their children using computers, technology rarely ever featured in any of the jobs they aspired their children to have. The sum of 'government job' or 'teacher' as a preferred occupation exceeded the combined sum of all other occupations, and there were only a handful of parents who said they would like their children to be engineers or professionals in the computer trade. More parents mentioned, 'computers will get my child respect' than said 'computers will get my child jobs.' Regardless of whether the two ideas were proxies for one another, this is an important difference to highlight. The computer was not seen as the tool that will get them a job; rather it was a device that was an indicator of modernity, of an ascendance in class.

\subsection{Overarching themes: Responsibility for schooling}

In our early work with state-run schools in Karnataka, we found conflicted ideas on who owned the schooling system, and consequently, whose primary responsibility a child's education was. Two important and often repeated sets of generalizatoins that emerged from rural parents' opinions about responsibility and ownership of schooling. The first generalization was that of the state schooling system as being weak, and therefore that moving to private schools even when those were poorer in resources than the state schools, was an act of proactive responsibility on part of a parent who could afford the luxury of giving up free education. The second opinion saw the state schooling system as being a benevolent provider of education in the hinterland. We found this to be an intriguing question, because it bore consequences for the ways in which parents were willing to invest in a child's education, but also in the perception of the school itself, and the perception of themselves as rightful customers.

Before looking at the issue in the rural milieu, we spoke to parents in middle-class urban households, and posed them the question, "Who is responsible for ensuring a child's education?" For most of them, the answer was obvious, "The parents." When we included the question in the free form conversations with parents in the rural schools that had been given CAL centers, the responses were very different.

We found that rural parents especially looked to teachers and to the government (including the village elected representatives) to be responsible for ensuring a child's good education. One perspective on this was given by an illiterate mother from Bellary, "We send our children to school because the teachers have been appointed and we trust them. They are educated, they must educate our children, too." The sense of individual disempowerment because of being illiterate is compensated in the minds of many by being part of a collective, which in turn explains the reliance on the village council. Another mother echoed the response of several others in Bangalore Rural, "They (the Panchayat, or village administrative body) are the elders here, the government has given them, and them only, the right to oversee the school."

This last point is of particular significance because in interviews with parents it was often clear that parents did not feel the school or teachers were individually answerable to them. This in fact goes back to the first generalization on responsibility referred to at the start of this section. Many parents in a village in rural Pondicherry where an early part of this work was done had started sending their children to a small private school set up directly across the state school. This private school had no fixed building, and untrained teachers and yet attracted a fair number of parents. The state school in comparison had excellent premises and provided children with free uniforms and bicycles if they made it past Class 9. When asked why they shifted their children, a parents responded, "The government school here is better in every way-bigger building, free uniforms, computers, meals - but I still removed my children from this school and sent them to the private school nearby, even though we have to walk to get there and the government school is right here. There, I visit the school every week; if I don't like something, I can tell the teacher."

This in fact ties in with the second generalization mentioned as well of the perception of schooling as being an act of benevolence from the school. Children got only what the government deemed reasonable-whether midday meals, computers, or free notebooks or uniforms. There was no sense of activism over poor service. ${ }^{4}$

The issue of responsibility over schooling and ownership of resources was deeply relevant to the attitude towards

\footnotetext{
${ }^{4}$ This was further supported by those respondents who cited wanting to consider private schools. For them, one of the key draws was the fact that the school is answerable to them, and therefore "more disciplined."
} 
computers. Many CAL centers were inaugurated by government officials. Similarly, village residents frequently expressed gratitude for the computers sent to their villages, unaware that these came from public outlays. In visiting a number of places where the computers were not working, the standard answer prevailed "The government has given these, it alone will fix them." We found in the interviews that this attitude goes beyond the computers into other realms that parents feel they have no control over-such as teacher absences or quality of instruction. So while a number of parents complained about un-rectified teacher shortages in their children's school, but none had ever protested or demanded action, nor was anyone clear on what role the Panchayat, which they sought out for such tasks, had the right to do.

There was little sense of ownership of the CAL centers, either the politicians or the Azim Premji Foundation (the agency that deployed the computers and trained the teachers on behalf of the government) were seen as the providers of the computers. This lack of sense of ownership and responsibility over the computers has already had consequences comparable to the unrectified teacher absences. For instance, several CAL centers were created with full initial funding and financial support for one center manager for the first year, with the assumption that the local community/parents would start supporting the operating costs of the CAL thereafter. Parents are asked to self-organize to pool for one CAL lab assistant's monthly wage, roughly about Rs. 1,500 , or US\$30, which translates to roughly Rs. 15 (US\$ 0.30) per parent per month in a school with 100 students in classes with access to computers. Despite a stated willingness to pay (and in this survey, parents stated a willingness to pay upto Rs. 50 a month for computers) the schools were unable to raise money for the CAL throughout most of Karnataka with the exception of some part of the schools along the affluent coastal areas. This was in part because the idea of paying the state school was completely new, and furthermore, the computers were not seen as owned by the community, but by the state and the school, thus not a financial responsibility of the parents.

Many functional aspects of how schools in rural areas operate further reinforce the separation of parents from ownership of their children's future in the schooling system. For instance in our interviews with both regular teachers and CAL center teachers we found both groups did not feel answerable to parents, and they felt that it was the block officers (government regional bureaucrats) that could question their conduct or operation of schools. This lack of teachers' sense of accountability to parents is well documented from several parts of India (Dyer 2000). The relationship between parents, teachers, and accountability in rural state schools is further complicated by the role of the teacher as a state official in the village, often doubling up for election duty or any other governmental work. This on one hand cuts out teaching time, and on another, puts the teacher in a position of power in the village.

A lot of parents in our sample spoke of the elected village panchayat as being the body that the schools were accountable to, and this is explained in the high proportion of parents looking at the panchayat as being responsible for children's schooling. In practice, the village panchayat itself has little real control over the teacher's appointment or longevity, and can only vote on matters of infrastructural spending in the school. We found in our discussions with teachers that in the more remote villages, the teachers were rarely ever locals, and had accepted the remote postings due to the desirability of the state job itself. Such teachers tended to be interested in moving out of these villages and towards either their own native towns or to urban areas with state schools.

On the whole, our interviews suggested that the sense of ownership and responsibility for the children's schooling and the physical artifact of the school itself were deeply related to the sense of power parents felt they had over each of these. In this light it is somewhat easier to explain the findings in Table 4 of the teachers and village council as perceived by parents to be more responsible for the child's schooling than themselves. We found very limited literacy among parents (less than 5\% from our sample had made it to $10^{\text {th }}$ grade) and that therefore the importance placed on an intermediary perceived as better positioned to control the quality and delivery of education. This puts the computers in an unusual position. On one hand, the sense of ownership and control over the computer is even more removed because of the abstraction of the device itself, as we see in section 4.3. This of course has led to the scenarios like parents' viewing computers as a gift from the government and managed through an intermediary like the computer teachers. Curiously, there was an unusual paradox in the facelessness of a computer. As opposed to the human intermediary of a teacher that parents felt they had no control over, the computer was seen as a neutral machine, with the ability to 'teach' the children, which helps set the tone for two discussions further down the paper. The first is parents' conception of spending on teachers vis-à-vis

Table 4 Respondents' perception of responsibility for child's education

\begin{tabular}{ll}
\hline & $(\mathrm{N}=165)$ \\
\hline Parents themselves & $15.8 \%$ \\
Teachers and the School & $43.6 \%$ \\
Panchayat (Village Council) School Committee & $29.7 \%$ \\
The Government & $18.2 \%$ \\
\hline
\end{tabular}

${ }^{\text {a }}$ Parents responded to who they felt was primarily responsible 
spending on additional computers. The second factor relates to the computer's ability to teach, or replace a teacher. This we discuss in greater detail in the following section.

\subsection{Overarching themes: Conceptions of computers}

In every village we conducted this research, the CAL center was the first ever instance of computers coming to the village. Early interviews with children indicated that information on computers were mainly from television and movies. There was a range in how people understood computers, but generally, there was a degree of basic understanding of what a computer is ("a machine to do calculations and other things"). However, we found that the sources of information about computers were diverse, and these in turn affected the individual parent's choices around computers.

We found that parents' ideas of where they had seen computers in use helped define for them ideas of what kinds of functions, and what kinds of people used computers. To several of the parents who cited their long term aspirations for their children as eventually becoming government officers, it was critical that the two top locations with computers encountered were directly associated with the government. Only one parent in our sample had ever actually used a computer, and only 8 from the 166 who spoke about the computers had a conceptual understanding of computers outside of basic billing functions (which alongside accounting was the most identified functional area of computers). As we see in Table 5, a fifth of the parents had never actually seen a computer, and from those that had seen computers in multiple places, a further fifth knew what a computer was, but did not know what its functions were.

Given that the actual knowledge of computer applications was generally low, the physical place of experience with computers became of particular significance, as did the

Table 5 Places where seen a computer / uses of computers familiar with

\begin{tabular}{lc}
\hline & $(\mathrm{N}=166)^{\mathrm{a}}$ \\
\hline Bank & $36.1 \%$ \\
Taluk (Administrative) Office & $31.9 \%$ \\
Bus Stand & $19.9 \%$ \\
Hospital & $16.9 \%$ \\
Factories & $16.3 \%$ \\
Electricity Bill Office & $11.4 \%$ \\
Market Place / Shops & $8.4 \%$ \\
Never actually seen a computer myself & $20.5 \%$ \\
\hline
\end{tabular}

${ }^{\text {a }}$ Multiple Answers allowed impressions of the users. We found that the association with people who used computers also became an important factor in the understanding of technology - this distinction came to be valuable in examining the nuances in the different conceptions of technology between parents working in the agriculture sector and parents working in factory jobs. We found that those who worked in agriculture had developed the greatest sense of aura around computers ("Computers can make you powerful; you can do anything nowadays with computers"). However, these also tended to be those respondents who did not actually know anyone in their immediate circles who used computers, and in discussion stated that most cases of computer use they had seen were from in front of the user, watching the user work on a computer rather than seeing what happens on a screen. Consequently, the aura of power assigned to computers was abstracted to the users.

In comparison, factory workers had a different view of computers. Despite the same sense that computer literacy was important, factory workers tended to have seen computers in action more often, and had a sense of homophily with a sub-section of the computer users. Factory workers interacted with office security guards who had been trained to use computers to assign gatepasses, or factory floor assistants who used computers for time-stamping made the machine less mysterious. Sharing the same class with the computer users arguably gave a different conception of where power and class really layand the importance of this distinction is seen in the contrast between agriculturist parents and factory worker parents' perceived importance of computers in future careers of their children vis-à-vis other skills and knowledge. Conversations with factory workers showed that they did not see computers as being inaccessible, given that people from their own classes and communities were daily computer users, and none the smarter or elevated from class for being able to do so. There was also not a serious sense that the use of computers could in itself to a lot to raise economic and social prospects. For factory workers, real power that separated the haves and have-nots derived from a different ability—being able to speak English.

4.4 CAL-specific themes: Perceived impacts of computers on the schools

The overarching themes help us set the understanding of the baseline factors that influence the general understanding of computers, we now turn to some of the perceived or real impacts of the CAL program that impact peoples' ideas about technology and its use.

We found a few themes in our early discussions as what the perceived impacts of the CALs had been on the school and on the villages more broadly, which we asked parents 
to comment on-all answers were free form responses both in the early rounds of interviews and in the final discussions. We coded the parents' responses into two broad categories - first, relating to the children and their schooling directly, and second, relating to adults' interactions with the schooling - thus changes in parents' involvement in schools, teachers' or school administrators' roles in schools.

The most consistent issue raised from our discussions across all the villages was that the CAL had caused a spike in the children's interest in the school. Although we do not have empirical attendance information on this, the responses from parents here are consistent with discussions with teachers who claimed that children were more regular in attending school since the CAL centers have started. One teacher in Shivanahalli, Bangalore Rural District, told us, "Whether or not they show up at any of the other days, whenever they know they have a computer class they are here without fail." A parent from the neighbourhood confirmed that the apparent nuisance of truant children was on the wane, "Earlier the kids would go to school in the morning and then run away after some time. Now they seem to be in the school all the time." In Table 6 below, we classify the problems by sampled districts to highlight the regional nuances in the perceived changes.

We can see that the largest component of perceived change in most locations is the perceived rise in children's interest in going to school. Since over half the sample was from locations where CAL programs have been in action for over 2 years, we can reasonably argue that we are not observing a first contact outcome. As we see in Table 6, over $20 \%$ of the entire sample thought that the overall environment for schooling had improved-thus either the teachers were more involved after the coming of the computers, or the parents saw themselves as more active/ interested (Codes 3 and 4 at 11\% each). This suggests larger environmental changes due to computers. A quote from a mother in Karahalli, Bangalore Rural, encompasses this variety of perceived impacts of the CAL center, "My children have become more active, they seem more interested in things and have even started directing their parents (referring to herself) in many things. They want to go to school everyday, even during the holidays to play with the computers. The whole village respects the school now."

Turning to the variations across the locations, we find a noticeable difference between the perceptions of change. Given the relatively small samples at Shimoga and Kodagu, we find the distinction between Bangalore Rural and Bellary sharpest. In the $92.6 \%$ of the respondents noted some positive change after the school getting computers, whereas in Bellary this figure was just over $50 \%$ of the sample. A bulk of this difference comes from the limited perceived impact on children in Bellary. When we examined the differences in the two districts, we found one important distinction - in Bangalore Rural, the teachers kept the computer center open on off-days, and children were encouraged to come into school and play with the computers. This was partly because the computer center managers (usually local youth) would open the computer center to learn to use the computers themselves, and sometimes to teach friends especially during summer break periods. In the process the CAL centers were also left open for the kids.

Our findings with children being perceived as more interested in being in school were somewhat expected, what came as surprising was that the school as a whole was perceived as having had a make-over now that the computers were in place. For instance, in Kodagu, we found that the schools themselves were being taken more seriously. Some of our interviews were at a site called Arecaud, where the families are not only poor and landless, but also migrant labourers from other states who do not speak the local dialect. Schools that cater to such

Table 6 Respondents' perception of changes in school due to CAL

\begin{tabular}{lllrrr}
\hline Location & Change Code 1 & Change Code 2 & Change Code 3 & Change Code 4 & No Changes \\
\hline BR $(n=68)$ & $23.5 \%$ & $45.6 \%$ & $13.2 \%$ & $10.3 \%$ & $7.4 \%$ \\
KO $(n=18)$ & $50.0 \%$ & $38.9 \%$ & $5.6 \%$ & $0.0 \%$ & $5.6 \%$ \\
SH $(n=20)$ & $10.0 \%$ & $30.0 \%$ & $20.0 \%$ & $25.0 \%$ & $15.0 \%$ \\
BE $(n=66)$ & $13.6 \%$ & $21.2 \%$ & $7.6 \%$ & $10.6 \%$ & $47.0 \%$ \\
Total $(n=172)$ & $20.9 \%$ & $33.7 \%$ & $11.0 \%$ & $11.0 \%$ & $23.3 \%$ \\
\hline
\end{tabular}

${ }^{\text {a }}$ Code 1: Responses indicate perception of children learning

${ }^{\mathrm{b}}$ Code 2: Responses indicate children more interested in going to school

${ }^{\mathrm{c}}$ Code 3: Responses indicate parents themselves more interested in school

${ }^{\mathrm{d}}$ Code 4: Responses indicate perception that school has improved overall

Y-axis codes: BR: Bangalore Rural, KO: Kodagu, SH: shimoga, BE: Bellary 
populations face a frequent student turnaround, since they have the problem of migration, primary language incompatibility and parental employment instability to deal with. One migrant father from West Bengal said with some surprise, "My children are now very interested in school and have started attending daily. So we cannot even go to any place with the family for visits because the children always want to go to school." In other words, taking a week off here and there to visit family away from the estates (usually in neighboring states) was in the past not an issue, but less so now with more demand from below." Parents are not often clear on exactly what it is that the children are doing better academically in school, but do realize that they are more interested in going to school.

In comparision, in Bellary where we found relatively less enthusiastic perceptions of the impacts of computers, parents' questioned the validity of computers being introduced based on their concerns about the quality of schooling more broadly. A mother in Joga, in the Bellary district said, "This is all a waste. Children in the $7^{\text {th }}$ grade don't even know how to read." She found no difference in her children's interest in schooling or in computer use. Other parents in Bellary also reiterated a number of existing problems with the access to teachers, and the lack of school management interest in programs like the CAL for children. Several parents claimed that the computers had rarely been used and were in need of repair most of the time the program was active.

We found that in Bellary the computers had not been given to the schools by the government as it had been in the other districts. Here, the machines came from a donation through the corporate social responsibility side of a major steel factory in the area. This meant that the participating schools did not go through planning phase typically undertaken by the implementation agency on behalf of the government (Azim Premji Foundation) including ensuring adequate teaching staff, community participation, building surveys etc. The schools thus chosen were picked through a sort of 'contest' whereas in comparison in Bellary schools were selected based on their proximity to the steel factory. Most of the schools in Bellary were not 'ready' for the CAL centers in terms of having the manpower required to run the computer classes and manage regular classes at the same time.

In exploring these questions, we find that the quality of although the general perception of the usefulness of computers is positive, the quality of initial experience with computers can be particularly important in setting expectations and opinions about the values of technology in the long term. This finding is further supported in subsequent sections where we compare respondents from Bellary with those from Bangalore Rural on the utility of computers visà-vis other forms of investment for children.
4.5 CAL-specific themes: Computers versus teachers, meals, english

It's a bit far fetched to compare the usefulness of computers with that of mid-day meals, but people working in ICTD in India can frequently expect to be asked how ICTD spending compares to other forms of welfare investment. So we asked parents at discuss in their own terms how they perceived the need for various kinds of investments in their own children's school. This is a tricky and politically charged question, and extremely difficult to measure, and parents' responses usually represented a combination of practical and symbolic considerations related to the economic and social needs of their own villages rather than something generalizable across the state of Karnataka.

The figures in Table 7 clearly tell an economic story. We find that the preference for meals (referring to the free midday meals offered to children in schools) moves in a direction inverse to computers, and also maps with the median incomes of the region (Bangalore reported the lowest incidence of financial difficulties in sending children to school; Kodagu reported the highest).

Within the realm of our small sample, the more a family needed meals, the less computers interested them. One father, a worker at an estate in Kodagu, when asked what he would do if the mid-day meals were stopped, stated blankly, "I would withdraw my child from the school. What is the use for him to go to school then?" His threat is not without merit. Participants who stated a preference notebooks or meals were a lot more concerned about the immediate consequences of not having access to those, than those who wanted more computers. In the past, the mid-day meal has been found to be one of the most successful schemes in getting children to school (Dreze and Kingdon 2001), and a lower proportion of people prioritizing meals does not map proportionately to the consequences of redirecting funds from one to the other. However, we did take a look to see how much parents would be willing to 'pay' if mid-day meals and computers both ceased to be

Table 7 Parents' perceptions of what is most needed in their local school

\begin{tabular}{lrccc}
\hline Location & Meals & Notebooks & Teachers & Computers \\
\hline BR $(\mathrm{n}=68)$ & $1.9 \%$ & $7.7 \%$ & $30.8 \%$ & $59.6 \%$ \\
KO $(\mathrm{n}=18)$ & $21.6 \%$ & $16.2 \%$ & $35.1 \%$ & $27.0 \%$ \\
SH $(\mathrm{n}=20)$ & $28.6 \%$ & $19.0 \%$ & $38.1 \%$ & $14.3 \%$ \\
BE $(\mathrm{n}=66)$ & $8.0 \%$ & $2.7 \%$ & $54.7 \%$ & $34.7 \%$ \\
Total $(\mathrm{n}=172)$ & $11.4 \%$ & $8.6 \%$ & $42.2 \%$ & $37.8 \%$ \\
\hline
\end{tabular}

y-axis codes: BR: Bangalore Rural, KO: Kodagu, SH: Shimoga, BE: Bellary 
state funded. We found that the $27.3 \%$ parents said they would basically refuse to pay for mid-day meals and feed the children at home, whereas $10.5 \%$ said they would not pay if the CAL became a paid service. The range that people were willing to spend went from a lower median of Rs. 5 in Shimoga to an upper median of Rs. 20 in Bangalore per month for mid-day meals, and from Rs. 7.50 in Shimoga to Rs. 50 per month for CAL lessons.

These figures require more investigation. We recognize that having a lengthy discussion on a range of issues that seem to revolve around computers can certainly induce bias. This brings us back to the issue of ownership, despite computer centers being in place for several years in many of the studied locations, periods of time when computers do not work or the CAL centers remain closed go without protest from parents. In contrast, according to the school administration, any delays in disbursing state-provided school uniforms or books causes significant grief and usually visits from parents. The political importance of computer centers in rural areas while significant in PR terms, is also not seen as sensitive politically-which is to say, withdrawing funding for free notebooks or uniforms would undoubtedly have negative consequences for local politicians, whereas stopping access to computers, less of a tangible physical artifact, does not pose the same dangers. It was clear in many interviews that parents had a sense of gratefulness towards the government for providing them with computers (research has shown this to be true for telecenter projects involving providing computers to villages (Lengyel et al. 2006) thus perceiving it as a gift than as a right.

It is instructive to look at the contrast between parents who prefer computers vis-à-vis those who do not. We asked parents if they had to choose between two "free" schools for their children - one with computers, but teaching in the local language, and another without computers, but teaching English, to see which they would pick (Table 8).

In continuation of the discussion we started in section 4.3, the data here shows us evidence of a greater perceived value in English language among parents who are factory workers. Besides the symbolic meaning of a class separation from English, the question of attainability for a specific skill also rises in discussions. One father noted, "I have seen my son working on the computer, making designs. He knows how to use it in less than 1 year. You see all these boys in the $7^{\text {th }}$ standard, after 3 years of learning English if you ask them for a glass of water in English they will run away. Even the English teacher will not talk to you in English."

Within the limited realm of what computing one can learn, in a CAL center, becoming a 'computer user' still seemed a much more attainable task to the parent than ever becoming an English speaker. There was an element of
Table 8 Comparison of perceived importance: Computers v/s English

\begin{tabular}{lll}
\hline Location & $\begin{array}{l}\text { Choice: Kannada } \\
\text { medium with } \\
\text { computers }\end{array}$ & $\begin{array}{l}\text { Choice: English- } \\
\text { medium without } \\
\text { computers }\end{array}$ \\
\hline BR $(n=68)$ & $96.2 \%$ & $3.8 \%$ \\
KO $(n=18)$ & $70.6 \%$ & $29.4 \%$ \\
SH $(n=20)$ & $65.0 \%$ & $35.0 \%$ \\
BE $(n=66)$ & $59.7 \%$ & $40.3 \%$ \\
Total $(n=172)$ & $73.5 \%$ & $26.5 \%$ \\
\hline
\end{tabular}

y-axis codes: BR: Bangalore Rural, KO: Kodagu, SH: Shimoga, BE: Bellary

shared class that one needed to become an English-speaker, one that was beyond the parent's reach. The most common complaint from English language teachers is the lack of other English speakers for the children to interact with in practicing the language. In the case of the computers, that is no longer (understood to be) valid. Everyone starts at the same level, there is a lot more one can learn from the device and possibly a good intermediary without recourse to a community. The device in itself is seen to have an impact on and a direct relationship with the child.

In speaking about computers, the single most common response for why parents would choose a computer school over English was that "children become intelligent" by learning computers. Parents also referred to a computer as a repository for wisdom. "By learning computers, we gain awareness," said a high-school graduate mother from Kodagu with a high-school degree, grooming her son to join the police someday. Whether or not her son ends up using computers in his work, the fact of his being familiar with technology makes him wiser.

Also aligned with some of the mentioned earlier ideas of omnipotence associated with technology, we found a sizeable number of parents who believed that the computers could be used to teach English where the teachers themselves had failed. The idea itself is not as far-fetched as it may initially come across to be, and a significant amount of academic research has already been devoted to using technology more efficiently to enhance language learning for the rural poor in the developing world \{Kam $2008 \# 111\}$. With a lot of the sampled villages, especially in Bangalore Rural, being in the periphery of the metropolitan economy of Bangalore largely around the technology sector, the idea of computer skills as being paramount was widely prevalent even among those most removed from any participation in that booming economy."There is respect only for people who have learnt computers nowadays, so computer education is of utmost importance," said one parent, in Bangalore Rural, rating computers practically at par with literacy. 
4.6 CAL-specific themes: Computers and power in the village

Various conceptions of power are consistently seen throughout the discussions of computers and aspiration. The technological interventions in villages impacted not just things directly related to education and human development, but a range of other issues, some of which emerged in the discussions with parents. We highlight here three specific vignettes that came out repeatedly in conversation and are worthy of further study.

The first surprising idea was that of dowry, and its connection to computer learning. The idea first came about in a discussion with a landowner in Bellary at the first stage of our research. Intuitively, we thought a computer-literate girl would probably have to pay a smaller dowry, but this was not the case.

The landowner told us that it was problematic to get a girl "too educated" in his village, since the more educated she became, the more expensive her groom. Since marriage is an important factor impacting the longevity of young females in schools, we spoke to parents about what they felt were the impacts of computers and education on dowry. In our analysis of the results, we found a split between about half the parents, frequently small farmers and independent landholders, who agreed with the Bellary landowner's thinking, and another half, frequently casual laborers, who felt that a computer-educated girl was valuable in the job market, and therefore could be married with a smaller dowry. One thing that most people agreed on however was that becoming computer literate positively affected the girl's choice. Striking a chord on the empowerment issue was a laborer father from Shimoga: He said, "A girl who has learnt computers is a more competent and powerful person and she does not have to accept whatever man the family gets for her, including one who wants more dowry. She can instead choose to wait till she gets the right man." The distinctions between small farrners and casual laborers' views on the impact of computers on a woman's marriage prospects cannot be empirically explained from our data, but one is that women are more likely to be workforce participants within casual laborer-led households thus the increased value in the workforce is valued positively. Agricultural land holding households have a comparatively lesser female workforce participation outside of the family.

Another complex question of power raised during the interviews was that of parents' generational gap with children. Many of the parents in our sample were illiterate and unlikely to ever individually access or use to any of the technologies their children were being exposed to. This could be true for most generation gaps in various parts of the world, but the extremity of poverty among parents against the dramatic changes in India's cultural and socio- economic conditions that the children may aspire to, but not the parents themselves, makes this an issue worth consideration. One statement we heard frequently was, "So what if we are illiterate, our children can say that they learned computers." Mothers spoke with mixed emotions about this for themselves, noting that the computers had made them wish they had a chance to go to school and learn about new things longer. However, the unusual effect is the diminished credibility of the parents. Already, being illiterates is a difficult thing for many parents to reconcile with, especially, in terms of authority both at home and in interactions with teachers in the schools. With the computers coming to the villages, this has gone to a new level, and is reflected in the responses of parents on the importance of teachers. One mother, while speaking of responsibility stated, "If we advise children, they do not listen to us, the only person they will listen to is the teacher," Both the mother and her husband are illiterate, working as agricultural labour.

\section{Conclusion}

This research intends to start a discussion on new perspectives on of thinking about computers, parents and development. In discussing computers, we found that the real impacts of CAL projects went far beyond learning questions into issues of expectations from the state, of class associations, and of fears.

As we emphasize here, these notions of technology are represented through a variety of means in the rural milieu. Homophily with other members of one's own class using computers reduced the sense of mystique among factory workers about computers, and in doing so, underlined their own contrast with parents more restricted to the agricultural domain. Then, parents' sense of mystique around computers despite not having a strong grasp of computer functionality, highlighted the powerful symbolic value of the in the rural space. Despite limited practical conceptualization of the application of computers, parents enthusiastically supported investments into computers as a means to social ascendancy. From the fairly standard responses of computers being able to bring access to jobs and respect in society, to the more ambitious, 'children can learn English from a computer,' all of these ideas held a common thread of an underlying class negotiation.

As is typical in interview and participant-observation based research, several key learnings from the project came from questions we had not anticipated. In conclusion, we highlight one that may have important consequences for a number of projects active in providing technology to children in developing regions. A unique revelation for us was parents' thoughts on computers as shared resources. Twenty of the parents who took part in the study, at least 
once described, completely unprompted, that the computer is public good, and should be in schools rather than at homes, or as something that serves best when it is shared by all the children. The typical follow-up to such a statement was the idea that teachers were better equipped than parents to guide and supervise children as they used a device that they themselves (the parents) did not understand at all. But several parents added on another layer of complexity to ittheir idea that computers are better used in groups, learning together. Although most parents did not discuss specifics of the device in learning questions, they did emphasize the importance of shared ownership and learning from one another, which applied across technological and nontechnological resources. Not surprisingly, ideas of shared ownership also extended into a conception of local egalitarianism brought about by technology. As one father in Shimoga said, "My child now sits in the same benches and uses the computer alongside the rich children of the village."

Acknowledgments Thanks to S. Santhosh and Sukumar Anikar for consistent support and intellectual input. This work has also benefited from discussions with several other members at the Azim Premji Foundation including Shripad Vaze, Prachi Gaur, and Indu Prasad. Thanks to Sudhama Rao at the Jindal Steel Works Foundation, and also to M. Yusuf, and S. Kotresh, MSW students at Gulbarga University for their valuable work on this project. We also thank the five blind commentators during two rounds of reviews, and the editors Balaji Parthasarathy and Krithi Ramamritham for their comments on the paper.

Open Access This article is distributed under the terms of the Creative Commons Attribution Noncommercial License which permits any noncommercial use, distribution, and reproduction in any medium, provided the original author(s) and source are credited.

\section{References}

Arunachalam, S. (1999). Information and knowledge in the age of electronic communication: a developing country perspective. Journal of Information Science, 25(6), 465.

Attewell, P., \& Battle, J. (1999). Home Computers and School Performance. The Information Society, 15(1), 1-10.

Becker, H. J. (2000). Who's Wired and Who's Not: Children's Access to and Use of Computer Technology. Future Of Children, 10(2), 44-75.

Benjamin, S., Bhuvaneshwari, R., Rajan, P. (2006). 'E-Titling' or an "Anti-Politics Machine" necessary to globalize Bangalore? International Conference on Enhancing Land Registration and Cadastre for Economic Growth in India, New Delhi, Centre for Science, Development and Media Studies (CSDMS).

Bhatnagar, S. C. (2000). Information and communication technology in development: Cases from India. Thousand Oaks, CA, USA: Sage.

Brewer, E., M. Demmer, et al. (2006). The challenges of technology research for developing regions. IEEE Pervasive Computing: 15-23.

Chandrasekhar, C. P., \& Ghosh, J. (2001). Information and communication technologies and health in low income countries: the potential and the constraints. Bulletin of the World Health Organization, 79(9), 850-855.
Coley, R., Cradler J., et al. (1997). Computers and classrooms: The status of technology in US schools. Policy Information Report.

Cuban, L. (2001). Oversold and underused: Computers in the classroom. Harvard University Press.

Culp, K. M., Honey, M., et al. (2005). A retrospective on twenty years of education technology policy. Journal of Educational Computing Research, 32(3), 279-307.

De, R. (2007). The impact of indian e-government initiatives: Issues of poverty and vulnerability reduction. Regional Development Dialogue, 27(2), 88.

Downes, T. (1999). Children's and parents' discourses about computers in the home and school. Convergence: The International Journal of Research into New Media Technologies, 5(4), 104.

Dreze, J., \& Kingdon, G. G. (2001). School participation in Rural India. Review of Development Economics, 5(1), 1-24.

Dyer, C. (2000). Operation Blackboard: Policy implementation in Indian elementary education. Oxford: Symposium Books.

Gandhi, R., Veeraraghavan, R. et al. (2007). Digital green: A participatory digital framework to deliver targeted agricultural information to small and marginal farmers. Second International Conference on Information Technologies and Development, Dec 2007, IEEE Conference Proceedings, Bangalore.

Ganguly, S., \& Pardesi, M. S. (2007). India rising: what is new delhi to do? World Policy Journal, 24(1), 9-18.

Garai, A., \& Shadrach, B. (2006). Taking ICT to every Indian village: Opportunities and challenges. New Delhi: One World South Asia.

Harris, R., Kumar, A. et al. (2003). Sustainable telecentres? Two cases form India. Information Technology in the Development Context. S. Krishna and S. Madon. Aldershot, UK, Ashgate: 124-135.

Inamdar, P. (2004). Computer skills development by children using'hole in the wall'facilities in rural India. Australasian Journal of Educational Technology, 20(3), 337-350.

Jensen, R. (2007). The digital provide: information (technology), market performance, and welfare in the South Indian fisheries sector. Quarterly Journal of Economics, 122(3), 879.

Kam, M., Ramachandran, D. et al. (2007). Localized iterative design for language learning in underdeveloped regions: the PACE framework. Proceedings of the SIGCHI conference on Human factors in computing systems. 1097-1106.

Keniston, K. (2002). Grassroots ICT projects in India: Some preliminary hypotheses. ASCI Journal of Management, 31(1).

Lawry, J., Upitis, R., et al. (1995). Exploring common conceptions about boys and electronic games. Journal Of Computers In Mathematics And Science Teaching, 14, 439-460.

Lengyel, G., Eranusz, E. et al. (2006). The Cserénfa experiment On the attempt to deploy computers and Internet in a small Hungarian village. The Journal of Community Informatics, $2(3$ (Special Issue: Telecentres)).

Linden, L., Banerjee, A. V. et al. (2003). Computer assisted learning: evidence from a randomized experiment. MIT Poverty Action Lab Working Paper Series, 5.

Lindlof, T. (1992). Computing tales: Parents' discourse about technology and family. Social Science Computer Review, 10, 291-301.

Linebarger, D. L., \& Chernin, A. R. (2003). Young children, parents, computers, and the internet. IT \& Society, 1(4), 87-106.

Meera, S. N., A. Jhamtani, et al. (2004). "Information and communication technology in agricultural development: a comparative analysis of three projects from India. Network Paper-Agricultural Research and Extension Network: 15pp.

Prensky, M. (2003). Digital game-based learning. Computers in Entertainment (CIE), 1(1), 21-21.

Ramamritham, K., Bahuman, A. et al. (2006). Innovative ICT Tools for information provision in agricultural extension (December 2005). Information and Communication Technologies and Development, 2006. ICTD '06. 
Resnick, M., Rusk, N. et al. (1998). The computer clubhouse: technological fluency in the inner city. high technology and low-income communities. D. Schon, B. Sanyal and W. Mitchell. Cambridge, MA, MIT.

Rosas, R., Nussbaum, M., et al. (2003). Beyond Nintendo: design and assessment of educational video games for first and second grade students. Computers \& Education, 40(1), 71-94.

Sathe, S. K., \& Desai, U. B. (2006). Cell phone based microcredit risk assessment using fuzzy clustering. Information and Communication Technologies and Development, 2006. ICTD'06. International Conference on, 233-242.

Selwyn, N. (2003). Doing IT for the Kids': Re-examining Children, Computers and theInformation Society'. Media. Culture \& Society, 25(3), 351

Selwyn, N. (2004). Exploring the role of children in adults' adoption and use of computers. Information Technology \& People, 17(1), $53-70$.

Singhal, A., \& Rogers, E. M. (2001). India's communication revolution: from bullock carts to cyber marts, Sage. CA: New Delhi; Thousand Oaks.

Thamizoli, P., \& Balasubramanian K. (2001). Information management and knowledge empowerment: MSSRF telecenters in
South India. The Journal of Development Communication, 12 (2).

Vasudevan, R. (2007). Changed governance or computerized governance? computerized property transfer processes in Tamil Nadu, India. Information Technologies and International Development, $4(1), 101-112$.

Wartella, E. (2000). Children and computers: New Techology, old concerns.

Joyojeet Pal is a Research Associate at the Center for Information and Society at the University of Washington. His recent research is primarily in the aspirational environment around technology projects in the developing world. He can be reached at joyojeet@g mail.com.

Meera Lakshmanan is an independent consultant on technology and education issues in Bangalore. She can be reached at meeragargi@g mail.com.

Kentaro Toyama is the Assistant Managing Director of Microsoft Research India, Bangalore. He can be reached at kentaro.toyama@, microsoft.com. 